\title{
A new thermal energy storage technology for power system ser- vices
}

Romano Acri ${ }^{1}$, Fulvio Bassetti ${ }^{2}$, Maria Carmen Falvo ${ }^{1}$, Letizia Magaldi ${ }^{2}$, Matteo Manganelli 1,* Lorenzo Romagnoli ${ }^{2}$, Federico Santi ${ }^{1}$

1 Sapienza University of Rome, DIAEE - Electrical Engineering Area; \{romanoalberto.acri, mariacarmen.falvo, matteo.manganelli, federico.santi\}@uniroma1.it

2 Magaldi Power; \{fulvio.bassetti, letizia.magaldi, lorenzo.romagnoli\}@magaldi.com

* Correspondence: matteo.manganelli@uniroma1.it;

\begin{abstract}
The decarbonization of the electrical energy sector is in progress for contrasting the climate changes, with a relevant increase of the Renewable Energy Sources (RES) power plants, mostly in Dispersed Generation (DG). The adequacy and the security of power systems, with a huge penetration of RES in DG is possible with a suitable integration of energy storage. In fact, energy storages are able to provide many different services for long-term adequacy and real time security. In this framework the present paper deals with a Thermal Energy Storage (TES) proposed for power system services. The technology presented is made up of modules containing a bed of fluidizable solid particles, which can store thermal energy from waste heat, process heat and/or from electricity. Stored thermal energy can be released, e.g. as superheated steam, for thermal uses or converted into electricity, by means of steam turbines. Some possible applications are then reported explaining advantages and limits.
\end{abstract}

Keywords: power systems, energy storage, electricity.

\section{Introduction}

To contrast climate changes, new energy policies are in progress worldwide, pursuing the goals set with the COP21 agreement [1-3]. The energy sector plays a decisive role in reducing $\mathrm{CO}_{2}$ emissions and limiting the increase of the Earth surface temperature. Targets of energy policies include the decarbonization of the energy sector, as a primary source, with its replacing with an ever-increasing penetration of Renewable Energy Sources (RES). The strong development of RES implies benefits in environmental impact of electricity generation, but, at the same time, it requires a deep change in the power systems: Large, concentrated power stations will give way to a plurality of smaller, distributed power plants, named Dispersed Generation (DG), characterized by non-programmable generation profiles.

Concerning the management and the operation of power systems, the development of RES DG will lead to new criticalities to be addressed, e.g., the reduction of the adequacy margin on the grids, a reduced power system inertia, and the lack of power plants ready for frequency and voltage control services. RES uncertainty also implies the need for greater reserve margins, with the related economic consequences for the entire system.

In this new scenario of the energy system, an important role is expected by storage systems. Various types of storage, with their respective characteristics and technical performances, can allow coping with the problems illustrated above $[4,5]$. Based on different technologies and features, storage can be implemented in different scales and at different levels of the power systems, ranging from large, concentrated storages to small, distributed storages.

In the present paper, a novel technology of Thermal Energy Storage (TES) is presented. The paper is organized in other 6 sections. Section 2 is dedicated to a literature 
review on different technologies of TES existing and under development. Section 3 provides a focus on storage services and technologies for power systems. Section 4 deals with the proposed TES technology, pointing out its main figures, its advantages and disadvantages and its positioning as energy storage technology. Section 5 includes some possible applications of the proposed TES. Section 6 contains the conclusions.

\section{Literature review}

From a general literature review, different technologies of TES are existing and under development, including particle beds [6], chilled water [7], phase-change materials (PCM) [8] (molten silicon [9] or molten salt [10]), building thermal mass, hot water (HW), or thermo-chemical materials (TCM) [8], oil or steam [10].

Applications of TES can be the coupling to concentrating solar power (CSP) [6,10] or combined heat and power (CHP) [11] plants, as a buffer to provide balancing services to the grid. Other applications concern off-grid buildings [7] or the use of buildings in demand response (DR) [12,13].

CSP is among the most attractive technologies, due to efficiency, environmental compatibility and scale-up potential, but lacks continuity of power generation due to the strong dependence on available solar radiation: A common solution is to incorporate a buffer TES system [10]. CHP is also interesting due to efficiency and opportunity to use a programmable RES (biomass) [14,15].

Ma et al. [6] present a modular, inexpensive TES system based on particles within a concrete silo, for concentrating solar power or grid energy storage. Meroueh et al. [9] present an electrically charged thermal energy storage system, releasing radiant heat to a supercritical Rankine cycle, to support the power grid against demand variations, using existing power units in thermal power plants to reduce capital cost. Bachmaier et al. [11] investigates the spatial distribution of TES systems in district heating networks, to increase flexibility of central CHP units and of households.DeValeria et al. [7] present a chilled water system for daily storage supporting seasonal chemical (hydrogen) storage, in a cluster of grid-independent buildings. Kohlhepp et al. [12] review large-scale grid integration of residential thermal energy storage for demand response (DR), via thermal storage attached to building heating, cooling, and air conditioning, or to domestic powerto-heat. The latter shows large and predictable DR capacities compared to smart appliances or vehicle-to-grid. Finck et al. [8] investigate an optimization strategy for scheduling various thermal energy storage technologies in an office building (building thermal mass, PCM, HW, TCM).

Mitsubishi Heavy Industries (MHI) also recently produced an article [16], referring to the use of storage systems for the flexibility of thermoelectric power plant. Attention is drawn to the way the Thermal Energy Storage can enhance electric power resilience when renewable energy supply is significant, estimating of energy-saving effects and economic efficiency.

\section{Storage services and technologies for power systems}

\subsection{Services}

The integration of storage in power systems is generally a measure that increases the flexibility of grids or of users connected to the grids (generators and passive customers), able to give fast responses, intended as implementation times, without major changes on the operation and interventions on the equipment.

A classification of storage technologies can be made according to the different services for the power system and its usefulness for the specific operators. In fact, each service can be of different utility for Transmission System Operators (TSO), for Distribution System Operators (DSO), for generators or passive customers. An international document that clarified and cataloged the various services that storage technologies can provide to the different power systems operators is the Department of Energy (DOE)/Electrical 
Power Research Institute (EPRI) Electricity Storage Handbook [17], according to this scheme:

1. Bulk energy services:

a. Electric energy time-shift (as a market instrument);

b. Electric energy supply capacity (to reduce the value of energy not supplied);

2. Ancillary services:

a. Reserves for frequency control (primary, secondary, and tertiary);

b. Voltage support;

c. Black start;

d. Other related uses, including quality of service;

3. Transmission and distribution infrastructure services:

a. Transmission upgrade deferral;

b. Transmission congestion relief;

4. Customer energy management services:
a. Power quality;
b. Power reliability;
c. Retail energy time-shift;
d. Demand charge management (in coordination with RES);
e. Stacked services (use case combinations).

The mentioned services can be provided to different entities within the power system, as it is illustrated in Table 1.

Table 1. Services provided by storage systems based on recipient entities

\begin{tabular}{ccc}
\hline Network operators (TSOs, DSOs) & Power plants & Consumers \\
\hline Time shifting & Time shifting & Time shifting \\
Power quality (voltage) & Primary frequency control & Emergency power supply \\
Power quality (frequency) & Secondary frequency control & \\
Reactive Power compensation & Tertiary Frequency control & \\
Fluctuation suppression & Voltage Control & \\
Grid voltage stability & Black start capability & \\
& Renewables forecast hedging & \\
\hline
\end{tabular}

\subsection{Technologies}

Storage technologies can be classified as follows:

1. Electrochemical energy storage: battery energy storage (BES);

2. Mechanical energy storage:

a. Pumping hydro energy storage (PHES);

b. Compressed air energy storage (CAES);

c. Flywheels;

3. Electrical energy storage:

a. Superconductive Magnetic Energy Storage (SMES);

b. Super-capacitors (supercaps);

4. Chemical energy storage:

a. Hydrogen;

b. Synthesis gas (syngas);

5. Thermal energy storage (TES): molten salts, solid particles, other.

Characteristics and features of each technology determine the suitability to perform certain services or to provide specific applications for the different power system entities. A classification exists between power-intensive and energy-intensive performance: powerintensive technologies are able to supply high power and low energy values, being suitable for fast, short applications; on the other hand, energy-intensive technologies can supply high energy, low power values, being suitable for slow, long uses.

The mentioned services are characterized by different response speed and discharge duration. The services listed by DOE/EPRI [17] can be classified as per Table 2. 
Table 2. Classification of services suitable for power-intensive or energy-intensive technologies

\begin{tabular}{cc}
\hline Power-intensive & Energy-intensive \\
\hline Primary frequency control & Time shifting \\
Voltage control & Peak shaving \\
Power factor correction & Grid congestion resolution \\
Power quality & Secondary active power reserve \\
& Tertiary active power reserve \\
& Black start \\
\hline
\end{tabular}


Table 3. Possible applications of different energy storage technologies, elaborated from [17]

\begin{tabular}{|c|c|c|c|c|c|c|c|c|c|c|}
\hline Role & Application & PHES & CAES & Flywheel & Li-ion & Sodium sulfur & Lead-acid & Vanadium redox flow & Hydrogen & Supercaps \\
\hline & Energy arbitrage & $\checkmark$ & $\checkmark$ & & $\checkmark$ & $\checkmark$ & $\checkmark$ & $\checkmark$ & $\checkmark$ & \\
\hline \multirow[t]{6}{*}{ System operator } & Primary response & & & $\checkmark$ & $\checkmark$ & $\checkmark$ & $\checkmark$ & $\checkmark$ & $\checkmark$ & $\checkmark$ \\
\hline & Secondary response & $\checkmark$ & $\checkmark$ & $\checkmark$ & $\checkmark$ & $\checkmark$ & $\checkmark$ & $\checkmark$ & $\checkmark$ & $\checkmark$ \\
\hline & Tertiary response & $\checkmark$ & $\checkmark$ & & $\checkmark$ & $\checkmark$ & $\checkmark$ & $\checkmark$ & $\checkmark$ & \\
\hline & Peaker replacement & $\checkmark$ & $\checkmark$ & & $\checkmark$ & $\checkmark$ & $\checkmark$ & $\checkmark$ & $\checkmark$ & \\
\hline & Black start & $\checkmark$ & $\checkmark$ & $\checkmark$ & $\checkmark$ & $\checkmark$ & $\checkmark$ & $\checkmark$ & $\checkmark$ & $\checkmark$ \\
\hline & Seasonal storage & $\checkmark$ & $\checkmark$ & & & & & $\checkmark$ & $\checkmark$ & \\
\hline \multirow[t]{2}{*}{ Network operator } & T\&D investment deferral & $\checkmark$ & $\checkmark$ & $\checkmark$ & $\checkmark$ & $\checkmark$ & $\checkmark$ & $\checkmark$ & $\checkmark$ & $\checkmark$ \\
\hline & Congestion management & $\checkmark$ & $\checkmark$ & & $\checkmark$ & $\checkmark$ & $\checkmark$ & $\checkmark$ & $\checkmark$ & \\
\hline \multirow[t]{3}{*}{ Customer } & Bill management & & & & $\checkmark$ & $\checkmark$ & $\checkmark$ & $\checkmark$ & $\checkmark$ & \\
\hline & Power quality & & & $\checkmark$ & $\checkmark$ & $\checkmark$ & $\checkmark$ & $\checkmark$ & $\checkmark$ & $\checkmark$ \\
\hline & Power reliability & & & & $\checkmark$ & $\checkmark$ & $\checkmark$ & $\checkmark$ & $\checkmark$ & \\
\hline
\end{tabular}




\section{Proposed storage technology}

\subsection{Features}

Magaldi STEM-RES [18] belongs to TES technologies. It consists of an insulated tank containing a bed of fluidizable solid particles capable of storing high temperature (over $600{ }^{\circ} \mathrm{C}$ ) thermal energy (Figure 1). The solid particles can be heated via steam coils or electrical resistors, in case it is desired to store thermal energy from heat or electricity, respectively. Stored energy is returned in the form of superheated steam, conveyed via the mentioned steam coils or via dedicated heat exchangers. Then, superheated steam can be expanded in a steam turbine, as in traditional steam power plants. STEM-RES is made up of modules with typical mass inventory of 500-1000 tons that, combining thermal and electrical charges simultaneously or not, allow to reach thermal capacity in one module of approximately 20 to $150 \mathrm{MWht}$, according to the desired temperature of produced steam.

Several modules can be coupled in parallel or serial configuration with limited land requirement, to increase thermal capacity and provide steam quality to match customer different needs. STEM-RES presently classifies Technology Readiness Level (TRL) 5-6, "Technology demonstrated in relevant environment", within the Horizon 2020 definitions. The time required to bring the technology to full maturity (e.g., TRL-8 or TRL-9) is relatively short and not determined by the technology itself but from the creation of a firstmover commercial application, where favorable market conditions are present; since the technology is modular and uses common industrial materials and components, it can be easily scaled. The bed of fluidizable solid particles allows to store thermal energy more easily ensuring response time in the order of minutes. When fluidized, the solid particles will behave as a fluid and the immersed elements (e.g. the steam coils and electrical heaters) can freely expand at high temperature in any direction without permanent deformations. Thanks to the solid particles properties, STEM-RES technology is open to reach very high temperature of storage media, allowing to couple with high performance cycles, like sCO2, with efficiencies in the order of $50 \%$.

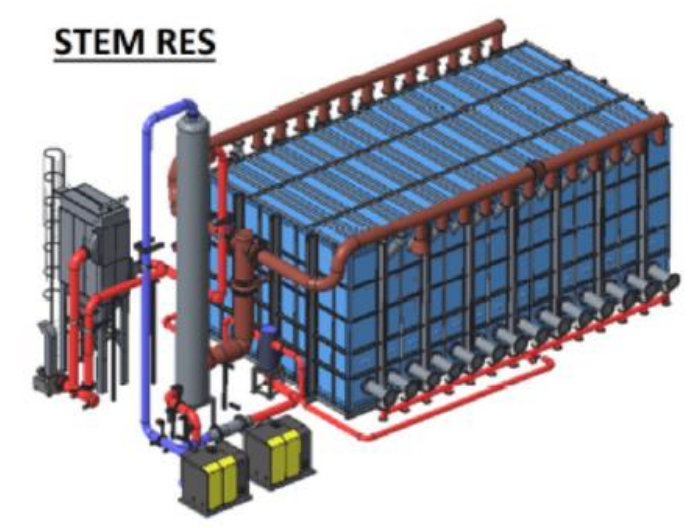

Figure 1. Typical STEM-RES modules

\subsection{Advantages and disadvantages}

STEM-RES has some intrinsic advantages, related to the technology itself, as follows:

- Modules do not use any rare, precious, polluting, or poisonous material: End-of-life decommissioning is therefore very simple, with almost total recovery of materials, in a circular economy perspective;

- The technical life of the modules is of decades, potentially over 40 years with appropriate replacement of the mechanical auxiliaries which are the components most subject to wear;

- The system has no dimensional constraints and can be easily expanded as it is made up of as many equal modules as desired; this can be useful in following the increasing storage requirement in the power system; 
- $\quad$ The plant can be installed anywhere without any geographic or orographic impact compared to other high-capacity energy storage systems, e.g., PHES, or CAES in caves;

- $\quad$ The plant has minimal territorial environmental impact, simplified permitting and licensing, short overall construction time and high social acceptability.

The main drawback of TES systems in power applications is the necessity to use a Rankine cycle to convert thermal energy to electricity, with relevant efficiency, in the range of $30 \%$ to $40 \%$, approximately half of that of PHES and one third of that of Li-ion BES.

\subsection{Positioning}

Ref. [19] maps energy storage technologies as a function of discharge time and capacity in gigawatt-hours (Figure 2). STEM-RES ranks between PHES and BES, similar to LAES and CAES, which, however, have a lower TRL.

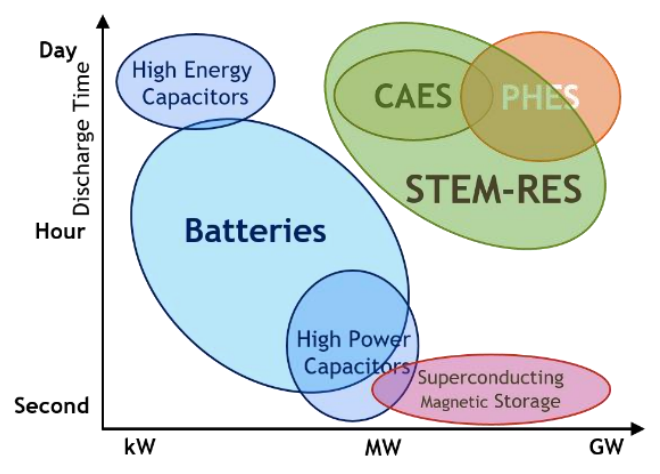

Figure 2. Positioning of energy storage technologies, elaborated from [19].

BES is currently receiving the greatest attention from industry and electric system owners and operators [20]. Li-ion BES is the most widespread technology, with highest specific energy and power in their field of application. However, STEM-RES is positioned among BES and PHES, in terms of power output and discharge time. Batteries are more suitable for shorter discharge time, up to 1-2 h.

\section{Analysis on possible applications}

\subsection{Integration in transmission and distribution grids as bulk energy storage}

The decarbonization of the power system and the diffusion of RES plants push for more flexible transmission and distribution grids, to face the variability of injected power and the reduction of reserves available by conventional generation for transient control and quality of service. This process will be slow and over span of years (horizon 2030). In a presumable first phase, RES share will be less than half of total energy generation. In this phase, the following entities will contribute to the flexibility of the power system, based on measures taken by grid operators worldwide:

- $\quad$ Large thermal power plants (particularly GT and CCGT plants);

- $\quad$ Large hydro power plants (particularly PHES plants);

- Aggregations of consumers or small power plants (DG), providing demand response reserve, based on their modulation capability [21].

Batteries, particularly Li-ion, are regarded as the most suitable technology. BESs should be sufficient to provide bulk energy services, as long as the excess of renewable energy occurs for a few hours per day, seasonally and in relatively modest quantities. Projects are in progress around the world on the integration of BES into the power system for different services, see e.g. [22,23].

In a presumable second phase, RES production will exceed $50 \%$ and the mentioned measures could not be sufficient. The integration of energy storage in the power system 
could be mandatory. The size of energy storage and the variety of services towards grid operators could increase based on the characteristics of the power system itself. BES could not be sufficient and suitable for a large-scale diffusion, technically, economically, and environmentally, considering the huge quantities of materials potentially necessary to manufacture batteries and then to be decommissioned. Different technologies will be necessary, including systems with larger storage capacity, possibly combined with batteries for power-intensive services. The most suitable technologies for high and very high capacity could be PHES, power-to-fuel/gas (including hydrogen), LAES, adiabatic-CAES (in caves or seabed balloons), TES (including STEM-RES).

Possible applications of STEM-RES could already be existing in the next decade, particularly in hybrid systems with Li-ion batteries, considering that:

- In developed and densely populated areas like Europe, the construction of new PHES plants can take up to ten years from decision to operation, including the authorization process and environmental impact assessment;

- $\quad$ Bulk energy storage technologies other than PHES still have a low TRL and at least a decade is required for a large-scale diffusion;

- $\quad$ PHES systems can outperform STEM-RES in power and energy capacity, based on orography and hydrogeology, but energy densities of PHES is much lower than STEM-RES (in the order of $1 \mathrm{~kJ} / \mathrm{kg}$ for PHES with $100 \mathrm{~m}$ head vs $320 \mathrm{~kJ} / \mathrm{kg}$ for STEM with $300^{\circ} \mathrm{C}$ temperature drop), lack modularity and suffer strong territorial constraints, leading to authorization difficulties and long development and construction times;

- $\quad$ STEM-RES has a maturity level of at least TRL5-6; design and construction of commercial STEM-RES systems are ordinary industrial activities; the implementation of a first-mover requires a short time, lower than that of other bulk energy storage technologies.

The last remark concerns inertia. In power systems with large penetration of RES and BES, there is a need for inertia, presently mainly provided by rotating masses of turbo generators. Research in converters is focusing on synthetic inertia, but the prediction of the behavior of power systems with numerous distributed converters and artificial inertia is difficult. Without any doubt, the presence of rotating machines remains a benefit for the regulation and safety of power systems. STEM-RES, making use of turbo generators, is useful in this regard.

These issues are stressed in small, weakly interconnected, or stand-alone power systems. In such systems, energy storage is mandatory in presence of RES.

\subsection{Integration in thermal power plants for flexibilization}

\subsubsection{Transformation of disused thermal power plants into storage hubs}

One possible application is in disused thermal power plants (whose number is destined to increase following the decarbonization of power systems) to recover power blocks and create a storage hub. Turbo generators groups can be recovered (with significant economic savings) and connected to STEM-RES modules, which can be installed e.g. in the areas dedicated to fuel depots. Storage hubs can be created with large capacity, already connected to grid nodes, with no further land use, and recovering existing facilities and equipment (Figure 3). Storage hubs can be hybrid, integrating STEM-RES and BES, providing both power-intensive and energy-intensive services.

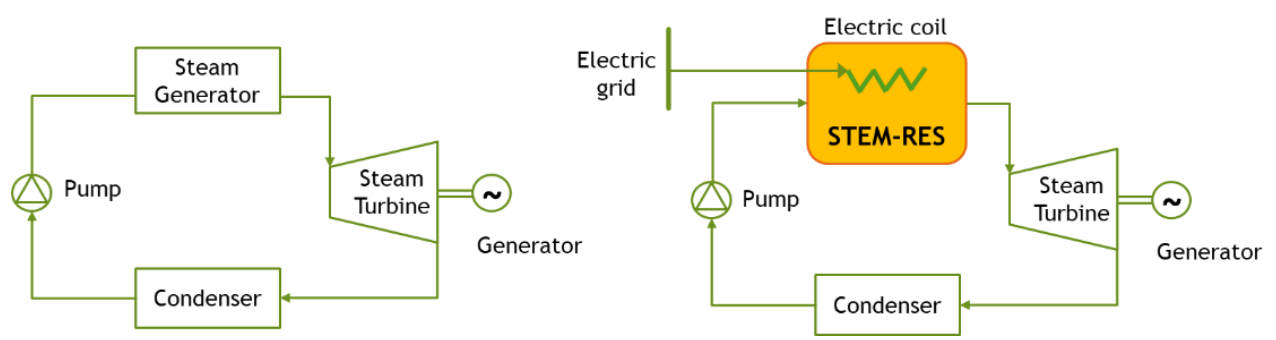


Figure 3. Schematic of implementation for recovering of disused steam power plants

\subsubsection{Improvement of existing thermal power plants}

Another possible application is in existing thermal power plants, to increase flexibility, in particular, to reduce the minimum acceptable load [16]. In fact, in certain market conditions, steam power plants are pushed to operate at minimum load, to avoid shutdowns and startups. This occurrence is increasingly frequent in advanced power systems, because of the increasing penetration of RES, with dispatching priority, and the consequent reduced dispatching of thermal power plants. Reducing the minimum acceptable load, thermal power plants can face this market condition more advantageously, in two ways:

1. Reducing the amount of electricity sold at minimum load point, thus reducing market losses in the day-ahead market;

2. Increasing the capacity ready to be made available to the TSO, sold as a flexibility service, thus increasing revenues in the dispatching services market.

3. Improving the load-following capability

4. Decoupling steam generator from steam turbine required load.

Since the minimum load of a steam power unit is normally determined by the steam generator, STEM-RES can be implemented to store excess thermal energy from the steam generator, keeping the steam turbine at its minimum load and reducing the minimum load of the power unit.

In practice, a certain number of STEM-RES modules (based on power plant size and characteristics) can be connected via steam flows to the steam generator or turbine, (Figure 4). When the unit operates at minimum load, high-pressure, high-temperature steam is spilled from the steam generator and supplies the modules; at non-minimum load, lower pressure, lower-temperature steam from the modules is fed for example into the LP stage turbine, increasing the power output with no further fuel consumption. Thermal energy charge of STEM-RES modules can be hybridized with electrical energy from the grid, taking advantage from the low electricity price periods, which are forecast to increase more and more along with the higher penetration of intermittent renewable energy sources.

The economic benefit depends on numerous factors, e.g., plant marginal production cost at minimum load compared to electricity market price in the time frame, revenues on flexibility in services markets, investment, and operating costs, and returns of the energy storage system.
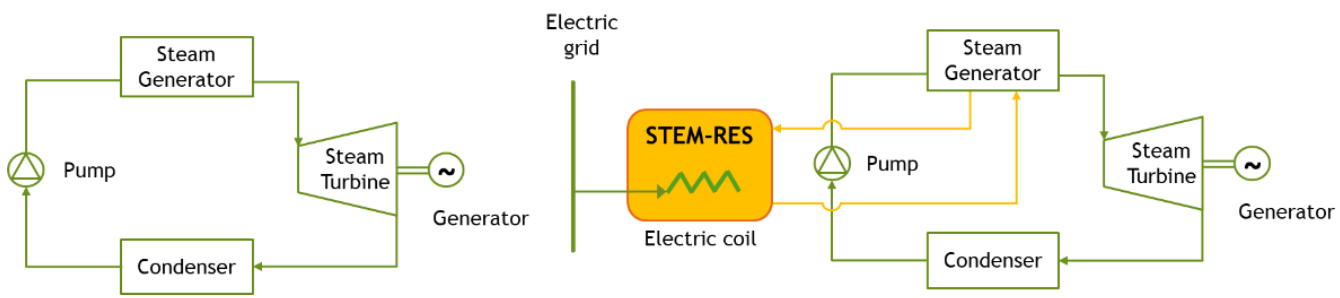

Figure 4. Schematic of implementation for improvement of existing steam power plants

\subsection{Integration in CHP systems}

The versatility of STEM-RES such as electric and/or thermal charge, the possibility of sizing the storage system according to needs and the wide range of operating temperatures, makes it suitable for the integration into existing Combined Heat and Power (CHP) plants serving industrial and civil users or district heating networks.

The benefits of this type of application can be summarized in the following points:

- Partially or fully decarbonize the fossil-fueled CHP segment through renewable electricity;

- Balancing of variable renewable energy in electrical systems with a high penetration of wind and photovoltaic systems, thus avoiding curtailment; 
- Increase the flexibility of existing CHP plants, by decoupling in time electricity and heat generation.

STEM-RES can be charged by the excess of electric energy, generated by variable renewable source plant during time when overgeneration occurs (and therefore when the electricity price is low/zero/negative), and by the excess of thermal energy generated by the CHP plant itself when the heat demand of the user decrease (Figure 5).

During discharge phase, STEM-RES can replace or integrate the thermal energy generation of the CHP plant.

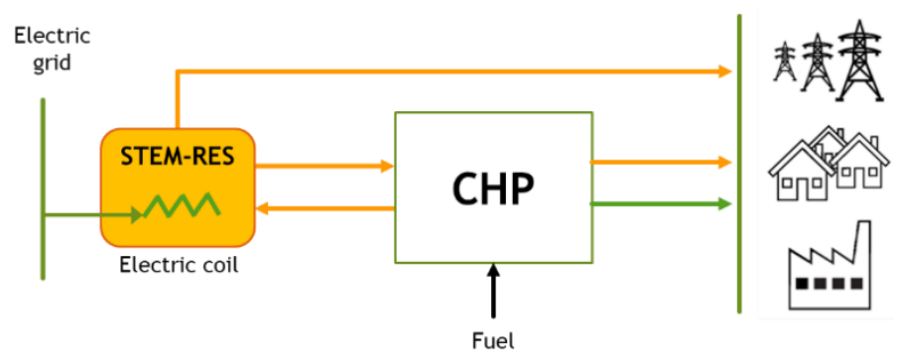

Figure 5 Implementation in existing CHP system

In a first phase, the STEM-RES system can be integrated into existing CHP plants to make the operational process more flexible, as mentioned above. In a scenario in which the penetration of variable renewable energies within the electric system is strong, it is possible to hypothesize to use the STEM-RES system in a stand-alone configuration for the combined production of thermal and electrical energy. In this case, coupling with a powerblock is necessary for the conversion of thermal energy into electricity (same assumption made in paragraph 5.2.1 are feasible for disused power plant recovery).

\section{Conclusions}

Following the analysis of the features of the TES proposed, the main conclusion is that the main advantages of STEM-RES over other technologies with similar positioning are:

- Absence of geographic/orographic restrictions, ease and brevity of authorization process (unlike PHES and CAES);

- $\quad$ Limited land use (approximately less than 1 ha per GWht);

- Absence of precious/rare/polluting/poisonous materials, easy disposal and recovery of components at end of life, technical life of many decades, low environmental and social impact;

- Modularity, possibility of territorially homogeneous installation (e.g. in grid nodes), expandability over time following increasing required storage capacity;

- Opportunity to recover decommissioned power units, with a view to circular economy;

- $\quad$ Relatively low investment cost (comparable to that of current Li-Ion batteries);

- Versatility, being able to take advantage of both electricity and thermal energy, both for charging the thermal storage system and for discharging both electricity through a turbo alternator unit, as well as thermal energy in the form of superheated steam.

The range of STEM-RES potential applications is wide both in the power systems and in all industrial processes in which there is a need for high temperature thermal energy storage.

Author Contributions: Conceptualization, M.C. Falvo and F. Santi; validation, F. Bassetti and L. Magaldi; formal analysis, F. Bassetti, M.C. Falvo, L. Magaldi and F. Santi; investigation, L. Romagnoli and R. Acri; resources, M. Manganelli, L. Romagnoli and R. Acri; data curation, L. Romagnoli and R. Acri; writing-original draft preparation, M.C. Falvo, M. Manganelli and F. Santi; writing - review and editing, F. Bassetti, L. Magaldi and L. Romagnoli; supervision, F. Bassetti, M.C. Falvo, L. Magaldi and F. Santi; project administration, F. Bassetti, M.C. Falvo, L. Magaldi and F. 
Santi; funding acquisition, L. Magaldi. All authors have read and agreed to the published version of the manuscript.

Conflicts of Interest: The authors declare no conflict of interest.

\section{References}

1. UNFCCC. The Paris Agreement. 2021.

2. Italian Ministry of Economic Development; Italian Ministry of the Environment and Protection of Natural Resources and the Sea; Italian Ministry of Infrastructure and Transport. Integrated national energy and climate plan. Italy, 2019.

3. IRENA. NDCs in 2020; 2019.

4. BloombergNef. Energy Storage Investments Boom As Battery Costs Halve in the Next Decade. Availabe online: https://about.bnef.com/blog/energy-storage-investments-boom-battery-costs-halve-next-decade/ (accessed on Jan 2021).

5. IRENA. Electricity storage and renewables: Costs and markets to 2030; 2017.

6. Ma, Z.; Davenport, P.; Zhang, R. Design analysis of a particle-based thermal energy storage system for concentrating solar power or grid energy storage. Journal of Energy Storage 2020, 29, 101382, doi:https://doi.org/10.1016/j.est.2020.101382.

7. DeValeria, M.K.; Michaelides, E.E.; Michaelides, D.N. Energy and thermal storage in clusters of grid-independent buildings. Energy 2020, 190, 116440, doi:https://doi.org/10.1016/j.energy.2019.116440.

8. Finck, C.; Li, R.; Zeiler, W. An Optimization Strategy for Scheduling Various Thermal Energy Storage Technologies in Office Buildings Connected to Smart Grid. Energy Procedia 2015, 78, 806-811, doi:https://doi.org/10.1016/j.egypro.2015.11.105.

9. Meroueh, L.; Chen, G. Thermal energy storage radiatively coupled to a supercritical Rankine cycle for electric grid support. Renewable Energy 2020, 145, 604-621, doi:https://doi.org/10.1016/j.renene.2019.06.036.

10. Yu, Q.; Li, X.; Wang, Z.; Zhang, Q. Modeling and dynamic simulation of thermal energy storage system for concentrating solar power plant. Energy 2020, 198, 117183, doi:https://doi.org/10.1016/j.energy.2020.117183.

11. Bachmaier, A.; Narmsara, S.; Eggers, J.-B.; Herkel, S. Spatial distribution of thermal energy storage systems in urban areas connected to district heating for grid balancing-A techno-economical optimization based on a case study. Journal of Energy Storage 2016, 8, 349-357, doi:https://doi.org/10.1016/j.est.2016.05.004.

12. Kohlhepp, P.; Harb, H.; Wolisz, H.; Waczowicz, S.; Müller, D.; Hagenmeyer, V. Large-scale grid integration of residential thermal energy storages as demand-side flexibility resource: A review of international field studies. Renewable and Sustainable Energy Reviews 2019, 101, 527-547, doi:https://doi.org/10.1016/j.rser.2018.09.045.

13. Tang, R.; Wang, S. Model predictive control for thermal energy storage and thermal comfort optimization of building demand response in smart grids. Applied Energy 2019, 242, 873-882, doi:https://doi.org/10.1016/j.apenergy.2019.03.038.

14. Gambarotta, A.; Manganelli, M.; Morini, M. A model for filter diagnostics in a syngas-fed CHP plant. Energy Procedia 2018, 148, 400-407, doi:https://doi.org/10.1016/j.egypro.2018.08.101.

15. Gambarotta, A.; Manganelli, M.; Morini, M. A model for the simulation of the gas cleaning system in a syngas-fed CHP plant. AIP Conference Proceedings 2019, 10.1063/1.5138817, doi:10.1063/1.5138817.

16. Yamamoto, K.; Domoto, K.; Tobo, M.; Kawamizu, T.; Yamana, T.; Ota, Y. Thermal Storage System to Provide Highly-efficient Electric Power Resilience in the Era of Renewable Energy; Mitsubishi Heavy Industries: 2020.

17. DOE/EPRI; NRECA. DOE/EPRI Electricity Storage Handbook; 2015.

18. Magaldi. Sistemi a concentrazione solare. Availabe online: https://www.magaldi.com/it/prodotti-e-soluzioni/sistemi-aconcentrazione-solare (accessed on Jan 2021).

19. Sloane, T. Energy Storage MythBusters (or 6 questions you won't need to ask). Availabe online: https://blog.fluenceenergy.com/energy-storage-technologies-mythbusters (accessed on Jan 2021).

20. Manganelli, M.; Nicodemo, M.; D’Orazio, L.; Pimpinella, L.; Falvo, M. Restoration of an Active MV Distribution Grid with a Battery ESS: A Real Case Study. Sustainability 2018, 10, doi:10.3390/su10062058. 
21. ARERA. Deliberazione 5 Maggio 2017, 300/2017/R/EEL (con integrazioni e modifiche apportate con le deliberazioni 372/2017/R/EEL e 422/2018/R/EEL) «Prima apertura del mercato per il servizio di dispacciamento alla domanda elettrica ed alle unità di produzione anche da fonti rinnovabili non già abilitate nonché ai sistemi di accumulo. Istituzione di progetti pilota in vista della costituzione del Testo Integrato Dispacciamento Elettrico (TIDE) coerente con il balancing code europeo». 2017.

22. Noce, C.; Pimpinella, L.; Distribuzione, E. Performances comparison inside the electric energy storage systems of Enel Distribuzione.

23. e-distribuzione. Il progetto Grid4EU. Availabe online: https://www.e-distribuzione.it/progetti-e-innovazioni/grid4eu.html (accessed on Jan 2021). 